\title{
Recent advances on attention deficit/hyperactivity disorder
}

\author{
Luis A. Rohde ${ }^{1}$, Ricardo Halpern²
}

\begin{abstract}
Objectives: To describe the main aspects of attention deficit/hyperactivity disorder, including history, epidemiology, etiology, neurobiology, clinical features, comorbidities, diagnosis, outcome and treatment.

Sources of data: Comprehensive, non-systematic review of the literature on attention deficit/hyperactivity disorder.

Summary of the findings: Attention deficit/hyperactivity disorder has a neurobiological basis, and is highly prevalent in children and adolescents. Treatment is very efficacious, including the use of medication in most the cases.

Conclusions: Pediatricians are in a privileged position to detect this disorder early and to start the initial management of less severe cases and of those not complicated by extensive comorbidities.
\end{abstract}

J Pediatr (Rio J). 2004;80(2 SuppI):S61-S70: Attention deficit hyperactivity disorder, hyperkinetic disorder, ADHD.

\section{History and epidemiology}

The first references to hyperactivity and attention deficit in the non-medical literature date back to the mid-19th century. ${ }^{1}$ The disorder was first described in Lancet by pediatrician George Still in $1902 .^{2}$ However, the nomenclature of this disorder has continually changed. In the 1940s, it was called minimal brain injury, which was replaced with minimal brain dysfunction in 1962, as findings were more associated with dysfunctions of neural pathways than with injury to them. ${ }^{3}$ The classification system used in psychiatry,

1. Associate professor, Universidade Federal do Rio Grande do Sul (UFRGS). Coordinator of the Programa de Déficit de Atenção/Hiperatividade (PRODAH), Hospital de Clínicas de Porto Alegre (HCPA), Porto Alegre, RS, Brazil.

2. Associate professor, Fundação Faculdade Federal de Ciências Médicas de Porto Alegre (FFFCMPA) and Universidade Luterana do Brasil (ULBRA). Specialist in Development and Behavior, Center for Development and Learning, University of North Carolina at Chapel Hill.

Financial support: This study was carried out with partial support from Fundo de Incentivo a Pesquisa (FIPE) of Hospital de Clínicas de Porto Alegre and from CNPq.
ICD $-10^{4}$ and DSM-IV, 5 share more similarities than differences regarding diagnostic guidelines, although they use a different nomenclature (attention deficit hyperactivity disorder in the DSM-IV and hyperkinetic disorders in ICD-10).

The prevalence of this disorder has been investigated in several countries and in all continents. The differences found in prevalence rates have more to do with the methodology used (type of sample, study design, source of information, age, diagnostic criteria, or how they are applied) than with transcultural diagnostic differences. 6,7 Therefore, national and international studies that use the DSM-IV criteria tend to find prevalence rates of around $3-6 \%$ in school-aged children.6,8 A detailed review on this topic can be found in Faraone et al. 8

The male/female ratio ranges from $2: 1$ in populationbased studies to $9: 1$ in clinical trials. This difference in prevalence rates may be probably due to the fact that girls have ADHD with a higher predominance of inattention and fewer comorbid symptoms of conduct disorder, causing less trouble to the family and at school, resulting therefore 
in fewer referrals to treatment. Studies that assess prevalence according to socioeconomic level including not only Caucasian patients are rare and often yield inconclusive results. ${ }^{9}$

\section{Etiology}

Despite the large number of studies, the precise causes of ADHD remain unknown. However, the influence of genetic and environmental factors has been widely accepted in the literature. ${ }^{10}$ Genetic contribution is substantial; as with most psychiatric disorders, several genes with little effect are believed to be responsible for genetic vulnerability (or susceptibility) to the disorder, in addition to different environmental factors. This way, the development and progression of ADHD in an individual seems to depend on which susceptibility genes are involved, on how much each of them contributes to the disease and on the interaction of these genes between themselves and with the environment. ${ }^{11}$

Although ADHD is characterized by symptoms of inattention, hyperactivity and impulsivity, it is quite a heterogeneous disease, at least at the phenotypical level. Probably, different cases with special phenomenology (clinical heterogeneity) also have etiological heterogeneity. For further details on the etiology of ADHD, see Roman et al. ${ }^{12}$

\section{Environmental factors}

Psychosocial agents that act on the child's adaptive functioning and general emotional health, such as family disagreements and presence of mental disorders in either parent, seem to play an important role in the development and persistence of the disease, at least in some cases. ${ }^{13}$ Biederman et al. ${ }^{14}$ found a positive association between some psychosocial adversities (severe marital conflict, low socioeconomic level, big family, parental crime, maternal psychopathology and placement in a foster family) and ADHD.

The investigation into an association between ADHD and pregnancy or childbirth complications has yielded discrepant results, but tends to support the idea that such complications (toxemia, eclampsia, fetal post-maturity, length of delivery, fetal stress, low birthweight, antepartum hemorrhage, poor maternal health) may predispose to the disorder. ${ }^{13}$ Recently, Mick et al. ${ }^{15}$ have observed a significant association between exposure to tobacco and alcohol during pregnancy and the presence of ADHD in children even after control for family psychopathology (including ADHD), social adversities and comorbidity with conduct disorder. Other factors, such as perinatal brain injury to the frontal lobe may affect attention, motivation and planning, being indirectly associated with the disease. ${ }^{16}$ Most of the studies on possible environmental agents only revealed an association of these factors with ADHD, but no clear relation between cause and effect could be established. 13

\section{Genetic factors}

A substantial genetic contribution in ADHD is suggested by classic genetic studies. Various family studies have been conducted about ADHD, having consistently shown a significant familial recurrence of this disorder. The risk for ADHD seems to be two times to eight times greater in parents of affected children than in the general population. ${ }^{13}$

All the evidence obtained from family studies does not rule out the possibility that familial transmission of ADHD has an environmental etiology. In this regard, studies with twins and adopted children are crucial to determine whether a characteristic is actually influenced by genetic factors. The concordance between twin pairs is nothing more than a measure of inheritability, which represents an estimate of which portion of the phenotype is influenced by genetic factors. ${ }^{11}$ Most of these studies found considerable concordance for this pathology, which was significantly higher between monozygotic twins than between dizygotic ones. The estimated inheritability is high, exceeding 0.70 in several studies, which suggests a strong genetic influence. ${ }^{11}$

Striking evidence of ADHD inheritability is provided by studies with adopted children, since they can distinguish between genetic and environmental effects more efficiently. Initial studies with adopted children found a significantly higher frequency of ADHD among biological parents of affected children than among foster parents. ${ }^{11} \mathrm{~A}$ prevalence of ADHD of approximately three times among biological parents compared with foster parents also has been observed recently. ${ }^{17} \mathrm{~A}$ higher prevalence of ADHD among biological parents than among foster parents of probands confirms the contribution of important genetic factors to the etiology of this disorder.

There has been an increased interest in molecular genetic studies about ADHD in the last few years. The major aim of these studies is the genes that encode components of the dopaminergic, noradrenergic and serotoninergic systems, since results obtained from neurobiological studies strongly suggest the involvement of these neurotransmitters in the pathophysiology of ADHD. 18

Most molecular studies on ADHD have focused on the dopaminergic system. Dopamine transporter gene (DAT1) was the initial candidate for these studies, as the transporter protein is inhibited by stimulants used in the treatment of ADHD. ${ }^{19}$ The first report on the association of DAT1 with ADHD was made by Cook et al. ${ }^{20}$ These authors investigated a variable number of tandem repeats (VNTR) polymorphism located in region $3^{\prime}$ of the gene. An association was detected with the allele of 480 bp (base pairs), which corresponds to 10 copies of a 40 -bp repeat (10R), using haplotype relative risk (HRR). Later on, several studies attempted to replicate this association. Although some negative reports exist, most studies managed to detect an effect of DAT1 on ADHD. The estimated effect for DAT1 is quite small, with an odds ratio between 1.6 and $2.8 .^{21}$ 
Another gene in the dopaminergic system that is widely investigated is the dopamine 4 receptor gene (DRD4). The great interest in this gene has resulted from its association with a novelty seeking personality dimension, probably related to ADHD. ${ }^{22}$ In addition, the product of this gene is located in brain regions whose functions are impaired by the disease. 23,24 The main polymorphism investigated in DRD4 is a 48-bp VNTR, located in exon 3, region that supposedly encodes an important functional domain of this protein. ${ }^{12}$ LaHoste et al. ${ }^{25}$ were the first to detect the association of this gene with ADHD. The allele with seven copies of the 48-bp repeat (7R), the same related to the novelty seeking personality dimension, was suggested as risk allele. Although many subsequent studies have reproduced the association with DRD4, their results are controversial. A recent meta-analysis ${ }^{26}$ suggested a combined odds ratio of 1.4 for family studies and of 1.9 for studies that used population-based controls.

Virtually all the other genes in the dopaminergic system have been investigated for association with ADHD, including genes that encode D2, D3 and D5 receptors, and enzyme genes related to dopamine metabolism. ${ }^{12}$ of these genes, the most promising seems to be the dopamine 5 receptor gene (DRD5). Lowe et al. ${ }^{27}$ carried out a joint analysis of samples from 12 research centers, showing a small but significant effect (odds ratio $=1.24 ; p<0.001$ ) for DRD5 gene on combined ADHD with predominance of attention deficit. However, the number of investigations for most of these markers is still small and therefore does not allow definitive conclusions.

Few molecular studies have been conducted so far with genes from the noradrenergic system. These studies focused mainly on the gene that encodes the dopaminebeta-hydroxylase (DBH) enzyme, or DBH locus, of which a TaqI restriction site located in intron 5 is the object of investigation. ${ }^{12}$ Although the functional meaning of TaqI restriction site on $D B H$, and of $D B H$ on ADHD are not known yet, the report of an association in two independent samples suggests contribution of $\mathrm{DBH}$ gene to the susceptibility to this disorder. ${ }^{28}$ Genes of some adrenergic receptors also were investigated in ADHD. Associations of genes that encode $\alpha 2 A$ (ADRA2A) and $\alpha 2 C$ (ADRA2C) receptors with high scores of $A D H D$ have been suggested in the literature. ${ }^{29}$ Additional investigations into these genes are necessary to confirm or not their influence on the etiology of ADHD.

Recently, a possible influence of the serotoninergic system on the etiology of ADHD has been investigated. Positive results in patients with this disorder were obtained for serotonin receptor $2 \mathrm{~A}$ genes (HTR2A) ${ }^{30}$ and serotonin transporter, 31,32 whereas no association was found for the gene that encodes tryptophan hydroxylase (TPH), which regulates serotonin synthesis. ${ }^{33}$ Effects of the interaction between 5-HTT and DRD4 genes on sustained attention in one-year-olds, ${ }^{34}$ and on the response to methylphenidate ${ }^{35}$ were observed in other studies. All these findings, albeit preliminary, indicate that the analysis of these and other genes in the serotoninergic system in different groups of ADHD patients may result in an important etiological contribution.

Thus, the study of the etiology of ADHD is still in its infancy. Even with regard to genetics, which has been extensively investigated, the results are contradictory. None of the investigated genes, not even DRD4 or DAT1, may be considered necessary or sufficient to the development of this disorder. This is greatly due to a unique etiological heterogeneity, represented by the high clinical complexity of the disease. In the future, the study of the etiology of ADHD will certainly include the determination of possible "subphenotypes" or "endophenotypes", in which this heterogeneity is low. 18

\section{Neurobiology}

The data on the neurobiological substrate of ADHD are derived from neuropsychological, neuroimaging and neurotransmitter studies. Although there seems to be an agreement that no abnormal finding in a single system of neurotransmitters may be held responsible for a syndrome as heterogeneous as ADHD, studies mainly indicate the involvement of catecholamines, especially dopamine and norepinephrine. A detailed review on this issue can be found in Rohde \& Riesgo. ${ }^{36}$

It is common knowledge that the process of brain maturation has a posteroanterior progression, that is, first there is the myelination of the visual pathway, whose developmental maturation window opens near the time of birth and closes at around the second year of life. Finally, myelination of anterior areas takes place. Therefore, from a neuronal developmental standpoint, a certain level of pure hyperactivity is acceptable in children with no injury, up to approximately the fourth and fifth years of life, as the prefrontal region only completes its myelination at this age. ${ }^{37}$

A recent structural neuroimaging study has revealed that the evolutional path of the brain regarding the increase in intracerebral volumes in ADHD children follows a parallel course with those who do not have the disease, but always with significantly smaller volumes, which suggests that the events that triggered the symptoms (genetic or environmental influences) occurred early on and were non-progressive. The differences between cases and controls did not seem to be related to the use of psychostimulants. 38

One of the first anatomical and functional theories that attempted to explain the neurobiology of ADHD described dysfunctions in the frontal areas and in the subcortical connections to the limbic system. Therefore, at the beginning, there was only one attentional system, and ADHD was regarded as a frontal inhibitory control over limbic structures. However, the theory of a single attention center - albeit extensively confirmed by neuropsychological, functional neuroimaging, and neurotransmitter studies may explain some but not all cases of ADHD. From an 
anatomical and functional point of view, there should be a neural circuitry with two attention systems: an anterior one, which seems to be dopaminergic and involves the prefrontal region and its subcortical connections (responsible for inhibitory control and executive functions such as working memory), and a posterior one, primarily noradrenergic (responsible for the regulation of selective attention). ${ }^{36}$ The locus ceruleus also plays a vital role in attention and is basically comprised of adrenergic neurons only, becoming very active in response to specific stimuli. 39

Despite the importance of the functions in both attention systems for the neurobiology of ADHD, direct implications of their reciprocal relations to this disorder are still scarce. Levy \& Farrow ${ }^{40}$ reviewed the prefronto-parietal network, which links the anterior attention system to the posterior attention system and is the anatomical and functional support for the working memory.

\section{Diagnosis \\ Clinical picture}

The classic triad of symptoms that characterize this syndrome are inattention, hyperactivity and impulsivity. Regardless of the classification system, children with ADHD are easily identified in clinics, schools and at home. The description of the triad of symptoms is shown in Table 1 (DSM-IV diagnostic criteria).

It should be underscored that inattention, hyperactivity and impulsivity as isolated symptoms may result from many problems related to relationships (with parents and/ or colleagues and friends), inappropriate educational systems, or may even be associated with other disorders that are commonly observed in childhood and adolescence. Therefore, for the diagnosis of ADHD it is always necessary to contextualize the symptoms in the child's history. Some clues that indicate the presence of ADHD are: a) length of symptoms of inattention and/or hyperactivity/impulsivity. Quite often, children with ADHD have a history of symptoms that start in preschool age, or at least a period of several months with intense symptoms; b) frequency and intensity of symptoms. For the diagnosis of ADHD, it is crucial that at least six symptoms of inattention and/or six symptoms of hyperactivity/impulsivity described above be frequently present (each of the symptoms); c) persistence of symptoms in several places and over time. Symptoms of inattention and/or hyperactivity/impulsivity have to occur in different environments (e.g.: at school and at home) and be constant during the study period. Symptoms that occur only at home or only at school should warn clinicians of the possibility that inattention, hyperactivity or impulsivity may simply reflect a chaotic family situation or an inappropriate educational system. Likewise, oscillating symptoms with asymptomatic periods are not characteristic of ADHD; d) clinically significant consequences on the child's daily activities. Symptoms of hyperactivity or impulsivity with no effect on child's daily activities may reflect different functioning or temperament styles other than a psychiatric disorder; e) understanding the meaning of the symptom. For the diagnosis of ADHD, it is necessary that a careful assessment of each symptom, and not only a list of symptoms, be made. For instance, a child may show difficulty following instructions due to an oppositional defiant behavior towards parents or teachers, which characterizes a symptom of an oppositional defiant disorder instead of ADHD. It is essential to check whether the child does not follow instructions because he/she cannot concentrate while they are being given. In other words, it is necessary to check whether the supposedly present symptom is correlated with the basic characteristics of the disease, that is, attention deficit and/or difficulty in inhibitory control. ${ }^{3}$

Clinical presentation may vary according to the stage of development. Symptoms related to hyperactivity/ impulsivity are more frequent in preschool children with ADHD than symptoms of inattention. As more intense activity is characteristic of preschool children, the diagnosis of ADHD should be made with caution before the age of six years. This, among other reasons, is why information on a child's normal development is essential for the psychopathological assessment in this age group. The literature indicates that symptoms of hyperactivity subside in adolescence, but symptoms of inattention and impulsivity are more intense in this period. ${ }^{41}$

\section{Diagnostic criteria}

The diagnosis of ADHD is basically clinical, based upon clear and well-defined operational clinical criteria, established by classification systems such as the DSM-IV (Table 1), or ICD-10. By conducting a study in our setting, Rohde et al. ${ }^{7}$ found indicative signs of the adequacy of DSM-IV criteria, reinforcing their applicability in our setting.

The DSM-IV proposes that at least six symptoms of inattention and/or six symptoms of hyperactivity/ impulsivity are necessary for the diagnosis of ADHD. However, it has been suggested that this number could be lowered in adolescents and adults, since these individuals may continue to show some significant deficit in their global development, even with less than six symptoms of inattention and/or hyperactivity/impulsivity. Thus, the number of symptoms for the diagnosis of adolescents is not so important as the impairment caused by these symptoms. The level of impairment should always be assessed based on the adolescent's potentialities and on the amount of effort necessary to maintain adjustment. ${ }^{3}$

The DSM-IV and ICD-10 include a criterion for the age of onset of symptoms causing impairment (before the age of seven years). However, this criterion derives only from the opinion issued by the committee's ADHD experts, without any scientific evidence that supports its clinical validity. ${ }^{42}$ It is recommendable that clinicians do not rule out the possibility of diagnosis in patients who have symptoms causing impairment before the age of seven years. 
Table 1 - DSM-IV diagnostic criteria for ADHD

\section{A. Either 1 or 2}

(1) six (or more) of the following symptoms of inattention have persisted for at least 6 months to a degree that is maladaptive and inconsistent with developmental level:

\section{Inattention:}

a) often fails to give close attention to details or makes careless mistakes in schoolwork, work, or other activities

b) often has difficulty sustaining attention in tasks or play activities

c) often does not seem to listen when spoken to directly

d) often does not follow through on instructions and fails to finish schoolwork, chores, or duties in the workplace (not due to oppositional behavior or failure to understand instructions)

e) often has difficulty organizing tasks and activities

f) often avoids, dislikes, or is reluctant to engage in tasks that require sustained mental effort (such as schoolwork or homework)

g) often loses things necessary for tasks or activities (e.g., toys, school assignments, pencils, books, or tools)

h) is often easily distracted by extraneous stimuli i) is often forgetful in daily activities (2) six (or more) of the following symptoms of hyperactivity-impulsivity have persisted for at least 6 months to a degree that is maladaptive and inconsistent with developmental level:

Hyperactivity:

a) often fidgets with hands or feet or squirms in seat

b) often leaves seat in classroom or in other situations in which remaining seated is expected

c) often runs about or climbs excessively in situations in which it is inappropriate (in adolescents or adults, may be limited to subjective feelings of restlessness)

d) often has difficulty playing or engaging in leisure activities quietly

e) is often "on the go" or often acts as if "driven by a motor"

f) often talks excessively

Impulsivity:

g) often blurts out answers before questions have been completed

h) often has difficulty awaiting turn

i) often interrupts or intrudes on others (e.g., butts into conversations or games)

B. Some hyperactive-impulsive or inattentive symptoms that caused impairment were present before 7 years of age.

C. Some impairment from the symptoms is present in 2 or more settings (e.g., at school [or work] or at home).

D. There must be clear evidence of clinically significant impairment in social, academic, or occupational functioning.

E. The symptoms do not occur exclusively during the course of a pervasive developmental disorder, schizophrenia, or other psychotic disorder and are not better accounted for by another mental disorder (e.g., mood disorder, anxiety disorder, dissociative disorder, or personality disorder).

\section{Types of ADHD}

The DSM-IV subdivides ADHD into three types: a) predominantly inattentive type; b) predominantly hyperactive-impulsive type; c) combined type. ${ }^{5}$ The predominantly inattentive type is more common in females and, together with the combined type, seems to have a higher impact on academic performance. Children with the predominantly hyperactive-impulsive type are more aggressive and impulsive than those with the other two types of $A D H D$, and tend to be unpopular and highly rejected by their peers. The combined type causes more impairment to global functioning, comparatively to the other two types. ${ }^{3}$

\section{Comorbidities}

Studies show a high prevalence of comorbidity between ADHD and disruptive behavioral disorders (conduct disorder and oppositional defiant disorder), which ranges from 30 to $50 \%$. The comorbidity rate also is significant in the following diseases: a) depression (15 to $20 \%$ ); b) anxiety disorders (around 25\%); c) learning disabilities (10 to $25 \%) .41,43$

Several studies have shown a high prevalence of comorbidity between ADHD and drug abuse or dependency in adolescence, especially in adulthood ( 9 to $40 \%$ ). It is argued whether ADHD alone is a risk factor for drug abuse and dependency in adolescence. The comorbidity of ADHD 
and conduct disorder is recognizably frequent, and conduct disorder is clearly associated with drug abuse/dependency. Therefore, drug abuse/dependency possibly occurs more frequently in a subgroup of adolescents with ADHD who also present with conduct disorder. In other words, the risk factor is not ADHD per se, but the comorbidity with conduct disorder. This issue therefore requires further investigation. 3

\section{Procedures for diagnostic evaluation at the pediatrician's office}

Pediatricians are the health professionals who follow patients longitudinally and can identify the signs and symptoms that might be suggestive of ADHD at an earlier stage. Several studies have demonstrated that the prevalence of ADHD at a pediatrician's office is similar to that found at a psychiatrist's office. ${ }^{44}$

The basis for diagnosis consists of patient's history, observation of the patient's current behavior and the account of parents and teachers about the child's functioning in the places he/she frequents. With regard to the source of information, there is poor agreement between informers (children, parents, and teachers) about the child's mental health. Children often do not inform about behavioral symptoms and have low testretest concordance for ADHD symptoms. Parents seem to be good informers for the diagnostic criteria. Teachers tend to provide too much information about ADHD symptoms, especially when another disruptive behavioral disorder is concomitantly present. With adolescents, the usefulness of the information given by teachers significantly decreases, as adolescents have several teachers (one for each subject) and each teacher spends too little time with each class, which prevents them from knowing each student well enough. As observed, the process of diagnostic evaluation necessarily involves collection of data from the parents, children, and teachers. ${ }^{3}$

Past clinical history of behavior is essential for diagnostic definition, since only a small number of patients present the characteristic signs and symptoms of ADHD during assessment. One should recall that the absence of symptoms at the pediatrician's office does not rule out the diagnosis. These children often are able to control the symptoms voluntarily, or during activities in which they are greatly interested. Therefore, many times, they can spend hours in front of the computer or videogame, but cannot spend a few minutes in front of a book in the classroom or at home. ${ }^{3}$

Lack of concentration and/or hyperactivity at school is one of the most frequent complaints at the pediatrician's office; which suggests more of a specific learning difficulty than an attention deficit. A detailed social and family history is of paramount importance. ${ }^{45}$ Pediatricians should pay attention to perinatal history, since various studies show a higher prevalence of ADHD in preterm babies and low birthweight infants. Careful follow-up of this risk group is important for the early identification of signs and symptoms that may indicate a possible diagnosis of ADHD. 46

The "classic history" of ADHD is shown in Table 2.

Table 2 - "Classic history" of ADHD
Infant

Preschool child

Schoolaged child

Adolescent
"Difficult infant", greedy, annoyed, difficult to comfort, greater prevalence of cramps, difficulties to eat and sleep.

More active than usual, adjustment difficulties, stubborn, annoyed and extremely difficult to satisfy.

Unable to focus, inattention, impulsive, inconsistent performance, presence or absence of hyperactivity.

Restless, inconsistent performance, unable to focus, memory difficulties at school, medication abuse, accidents.
In clinical pediatric practice, only the general impression about the patient is not enough for establishing or ruling out the diagnosis. Short consultation time combined with other acute clinical symptoms may hamper a more accurate evaluation. It is recommended that whenever some behavior that might interfere with patient's functioning at school or at home is noticed, the pediatrician should focus on the assessment of patient's development.

Besides clinical history, the use of scales for signs or symptoms of ADHD and behavioral disorders is widely accepted, although pediatricians do not employ them on a routine basis. An instrument designed for the observation of behavior by teachers (e.g.: Conners teaching rating scale $)^{47}$ may be quite useful in data collection. Levine ${ }^{48}$ devised a set of questionnaires to be used by pediatricians, which includes questions about attention and behavior, with the aim of systematizing data collection and offering a detailed profile of the child's attention characteristics. Pediatricians should not lose track of child's development, which goes beyond their biological vulnerability to ADHD. Child's interaction with the environment and his/her family may eventually contribute to diagnosis, in addition to determining the quality and success of interventions. 49

Still regarding additional evaluation, hearing and visual assessment are fundamental, as deficits in sensory functions may result in important attention and hyperactivity problems. Neurological screening is relevant for the exclusion of brain disorders that might mimic ADHD and often is valuable to reinforce the diagnosis. The data obtained from evolutional neurological screening are important. 50 As far as 
psychological testing is concerned, Wechsler Intelligence Scale for Children ${ }^{51}$ allows for a cognitive evaluation of the child, being useful in differential diagnosis between mental retardation and ADHD. Other prevalent disorders such as the fragile $X$ syndrome also have to be ruled out, as this disorder may cause attention deficit, hyperactivity and impulsivity. Other neuropsychological tests (e.g.: Wisconsin card-sorting test, continuous performance test - CPT or Stroop test), as well as neuroimaging exams (CT scan, magnetic resonance, or cranial SPECT) are still part of the research and not of clinical asssesment. ${ }^{41,52}$

\section{Outcome}

Formerly, children with ADHD were believed to overcome their symptoms when they reached puberty. However, recent prospective studies that followed up children with ADHD show persistence of the diagnosis in up to $70-80 \%$ of cases in initial to intermediate adolescence. 53,54 Conservative estimates state that approximately $50 \%$ of adults diagnosed as having ADHD in childhood continue to have significant symptoms associated with functional impairment. Hyperactivity decreases during development, but attention deficits and impulsivity, especially cognitive impulsivity (acting before thinking) ${ }^{54}$ still persist.

Throughout development, ADHD is associated with an increased risk of low school performance, repeating a year, expulsion and suspension from school, difficult relationships with family and friends, development of anxiety, depression, low self-esteem, conduct disorders and delinquency, early experimentation with and abuse of drugs, car accidents and speed tickets, as well as difficulty establishing relationships in adulthood, in marriage and at work. ${ }^{24}$ Nevertheless, as already mentioned, part of this outcome may be associated with the comorbidity with conduct disorder and not only with ADHD.

\section{Treatment}

Treatment of ADHD consists of a multiple approach, including psychosocial and psychopharmacological interventions. Recently, the subcommittee on ADHD of the American Academy of Pediatrics has published guidelines for clinical pediatricians on the treatment of ADHD. 55 These guidelines consist of five basic principles:

1) Pediatricians should establish a treatment program that acknowledges ADHD as a chronic disease;

2) Pediatricians, along with parents, children and teachers, should specify the aims regarding treatment outcome;

3) Pediatricians should recommend the use of stimulants and/or behavioral therapy, if appropriate, to minimize target symptoms in children with ADHD;

4) When the selected management does not meet the established goals, pediatricians should reassess the original diagnosis, and check whether all appropriate treatments were used, treatment adherence, and the presence of comorbidities;

5) Pediatricians should systematically give children with ADHD a feedback, monitoring the established goals and adverse events through the information obtained from the children themselves, family and school.

With regard to psychosocial interventions, it is fundamental that pediatricians educate the family about the disorder, giving them clear and accurate information. An example of informative literature for families can be found in Rohde \& Benczick. ${ }^{56}$ Many times, parents have to go through a training program on behavioral interventions, so that they learn how to deal with their children's symptoms. It is important that parents know the best strategies so as to help their children organize and plan their activities. For instance, these children need a study environment that is quiet, consistent, and does not have many visual stimuli. In addition, these programs should offer training in specific techniques in giving commands, strengthening the social adaptive behavior, and minimizing or eliminating maladapted behavior (e.g.: through positive reinforcement). 55

Interventions at school also are important. In this regard, teachers should ideally be aware of the necessity of a well-structured classroom, with few students. Consistent daily routines and a predictable school environment help these children to keep their emotional control. Active teaching strategies that combine physical activity with the learning process are essential. Tasks should not be too long and have to be explained step by step. It is important that students with ADHD have as much personalized attention as possible. They should sit in the front row, close to the teacher and far from the window, that is, in a place where they have fewer chances of getting sidetracked. Quite often, children with ADHD need recap classes to go over some lessons. This occurs because they already have learning gaps at diagnosis, due to ADHD. Sometimes, these children need psychopedagogical counseling that is focused on their learning style, for instance, aspects regarding the organization, timing and planning of activities. Psychomotor re-education is indicated for improved control of movements. 3,41

In psychosocial interventions focused on children and adolescents, cognitive-behavioral therapy is the most widely studied modality, with scientifically proven efficacy in the treatment of central symptoms (inattention, hyperactivity, impulsivity), and associated behavioral symptoms (opposition, defiance, stubbornness), especially behavioral treatments (see Knapp et al. 57 for a detailed review on this topic). Among behavioral treatments, parental training seems to be the most efficient modality. However, recent results of the MTA study (multicenter and well-designed clinical trial that followed up 579 children with ADHD for 14 months, divided into four groups: drug therapy, behavioral psychotherapy with children and 
guidance for parents and teachers, combined approach, and community-based treatment) clearly showed a higher efficiency of drug therapy in the treatment of central symptoms compared to psychotherapy and the communitybased approach. The combined approach (drug therapy + behavioral psychotherapy with children and guidance for parents and teachers) did not demonstrate higher efficiency in treating central symptoms comparatively to drug therapy. ${ }^{58} \mathrm{~A}$ more careful interpretation of results suggests that proper drug therapy is essential to the management of ADHD.

With regard to psychopharmacological interventions, the literature clearly indicates stimulants as first-line treatment for ADHD. 59 There are over 150 methodologically sound controlled studies showing the efficacy of these drugs. ${ }^{60}$ In Brazil, methylphenidate is the only commercially available stimulant. Therapeutic dose ranges from 20 to $60 \mathrm{mg} /$ day. As methylphenidate has a short half-life ( 3 to 4 hours), it may be administered three times a day; one in the morning, another one at midday, and the last one in the evening. This is especially important in those patients with tasks that require attention at the end of the day. Some patients do not tolerate the third dose, and have remarkable insomnia as a result. These patients should receive the medication twice a day. In some of these cases, combination with clonidine may bring some benefits. ${ }^{61}$ Two formulations with a long-lasting effect and given in a single dose will soon be available in Brazil. One of them releases two "pulses," mimicking the administration of short-acting methylphenidate twice a day. The other formulation consists of long-acting methylphenidate (OROS system), whose effect lasts for up 12 hours. The innovative capsule technology allows constant release of the drug, avoiding variations in serum concentrations. Around $70 \%$ of ADHD patients have an appropriate response to and good tolerance of stimulants, with reduction of at least $50 \%$ of basic symptoms. 60 The most common adverse effects associated with the use of stimulants are: loss of appetite, insomnia, irritability, headache, and gastrointestinal distress. ${ }^{60}$ Controversies over the use of methylphenidate include: a) interference with growth recent studies have shown that the use of methylphenidate does not significantly change growth. Adolescents with ADHD treated or not with methylphenidate reach late adolescence with similar height; ${ }^{62} \mathrm{~b}$ ) potential abuse of methylphenidate - a recent meta-analysis clearly shows a significantly higher prevalence of abusive use/drug dependency in adolescents with ADHD who were not treated with stimulants compared to those who received stimulants. ${ }^{63}$ However, several studies have suggested the possibility of inappropriate use of stimulants by persons who do not suffer from ADHD; c) length of treatment - indications for medication-free periods, or for medication discontinuation during vacations from school are controversial. The discontinuation of methylphenidate use on weekends may be indicated for those children in whom symptoms are more detrimental to school performance, or for those adolescents in whom the control over the use of alcohol or illicit drugs is difficult on weekends. ${ }^{64}$ Discontinuation is indicated when the patient remains asymptomatic for about one year, or when symptoms improve substantially. Medication is discontinued in order to assess whether it is necessary to maintain the drug therapy.

Over 25 studies show the efficacy of tricyclic antidepressants in the treatment of ADHD. Once again, most studies include school-aged children. ${ }^{60}$ Clinically, tricyclic antidepressants are indicated in cases in which there is no response to stimulants and in the presence of comorbidity with tic disorders or enuresis. The following aspects related to the use of tricyclic antidepressants should be underscored: a) dose - the appropriate dose of imipramine ranges from 2 to $5 \mathrm{mg} / \mathrm{kg} /$ day. Underdoses of tricyclic antidepressants for the treatment of children is a common practice in our setting; b) cardiotoxic effects the international literature describes some cases of sudden death in children receiving desipramine. Very likely, these deaths are not directly related to the use of the medication. However, to be on the safe side, any child receiving tricyclic antidepressants should be electrocardiographically monitored before, during and after treatment. 65

Some studies also demonstrate the efficiency of other tricyclic antidepressants in treating ADHD, especially of buproprion. The dose of buproprion ranges from 1.5 to 6 $\mathrm{mg} / \mathrm{kg} /$ day, given in two or three doses; doses above 450 $\mathrm{mg} /$ day remarkably increase the risk of seizures, which are the main restriction on its use. Major side effects include agitation, dry mouth, insomnia, headache, nausea, vomiting, constipation and tremors. 66

Recently, a meta-analysis on the use of clonidine in ADHD found a positive effect on symptoms; the efficiency of clonidine can be compared to that of tricyclic antidepressants. ${ }^{67}$ Its use is indicated in the presence of comorbidities for which the use of stimulants is contraindicated or when stimulants are not tolerated. Doses range from 0.03 to $0.05 \mathrm{mg} / \mathrm{kg} / \mathrm{day}$ and the major contraindication is preexistence of cardiac conduction diseases, due to its side effects on the cardiovascular system . ${ }^{61}$ Nevertheless, it has been clinically combined with stimulants, especially in cases in which the individual use of stimulants causes sleep disorders or symptom recurrence at the end of the day.

Atomoxetine, recently approved by FDA, is a new pharmacological option for the treatment of ADHD, and should be available in Brazil very shortly. Atomoxetine is a non-stimulant drug and a selective norepinephrine reuptake inhibitor, with low affinity for other receptors and neurotransmitters. It reaches its peak serum concentration within 1 to 2 hours with a half-life around five hours. The average dose is of $1.4 \mathrm{mg} / \mathrm{kg} /$ day. Clinical trials indicate that it is efficient even with a single daily dose. So far, atomoxetine has been investigated in approximately 2,500 children and adolescents with ADHD in open-label and 
controlled studies (four studies). In all these studies, this drug was noticeably superior to the use of placebo in reducing the basic symptoms of ADHD and has proved to be safe and well tolerated, with discontinuation due to adverse effects in less than $5 \%$ of the cases. 68

\section{References}

1. Hoffmann H. Der Struwwelpeter. Berlin: DBGM; 1854.

2. Still GF. Some abnormal psychical conditions in childhood. Lancet. 1902;1:1008.

3. Rohde LA, Barbosa G, Tramontina S, Polanczyk G. Transtorno de déficit de atenção/hiperatividade: atualização diagnóstica e terapêutica. Rev Bras Psiquiatr. 2000;22 Supl 2:7-11.

4. Organização Mundial de Saúde. Classificação e Transtornos Mentais e de Comportamento da CID-10: Descrições clínicas e diretrizes diagnósticas. Porto Alegre: Editora Artes Médicas; 1993.

5. American Psychiatric Association. Diagnostic and Statistical Manual of Mental Disorders. 4th ed. Washington: American Psychiatric Association; 1994.

6. Rohde LA, Biederman J, Busnello ED, Zimmermann H, Schmitz M, Martins S, et al. ADHD in a school sample of Brazilian adolescents: a study of prevalence, comorbid conditions and impairments. J Am Acad Child Adolesc Psychiatry. 1999;6: 716-22.

7. Rohde LA, Barbosa G, Polankzick G, Eizirik M, Rassmussen E, Neuman R, et al. Factor and latent class analyses of DSM-IV ADHD symptoms in a school sample of Brazilian adolescents. J Am Acad Child Adolesc Psychiatry. 2001;40:711-8.

8. Faraone SV, Sergeant J, Gillberg C, Biederman J. The worldwide prevalence of ADHD: is it an American condition? World Psychiatry. 2003;2:104-13.

9. Golfeto JH, Barbosa G. Epidemiologia. In: Rohde LA, Mattos P, editores. Princípios e Práticas em TDAH. Porto Alegre: Artes Médicas; 2003. p. 15-34.

10. Tannock R. Attention-deficit/hyperactivity disorder: advances in cognitive, neurobiological, and genetic research. J Child Psychol Psychiat. 1998;39:65-99.

11. Thapar A, Holmes J, Poulton K, Harreington R. Genetic basis of attention-deficit and hyperactivity. Br J Psychiatry. 1999;174: 105-11.

12. Roman T, Schmitz M, Polanczyk G, Hutz M. Etiologia. In: Rohde LA, Mattos $P$, editores. Princípios e Práticas em TDAH. Porto Alegre: Artes Médicas; 2003. p. 35-52.

13. Faraone SV, Biederman J. Neurobiology of attention-deficit/ hyperactivity disorder. Biol Psychiatry. 1998;44:951-8.

14. Biederman J, Milberger S, Faraone SV, Kiely K, Guite J, Mick E, et al. Family-environment risk factors for ADHD: a test of Rutter's indicators of adversity. Arch Gen Psychiatry. 1995;52: 464-70.

15. Mick E, Biederman J, Faraone S, Sayer J, Kleiman S. Casecontrol study of ADHD and maternal smoking, alcohol use, and drug use during pregnancy. J Am Acad Child Adolesc Psychiatry. 2002;41:378-85.

16. Levy F, Barr C, Sunohara G. Directions of aetiologic research on attention-deficit/hyperactivity disorder. Aust N Z J Psychiatry. 1998;32:97-103.

17. Sprich S, Biederman J, Crawford MH, Muncy E, Faraone SV. Adoptive and biological families of children and adolescents with ADHD. J Am Acad Child Adolesc Psychiatry. 2000;39: 1432-7.

18. Castellanos FX. Toward a pathophysiology of attention-deficit/ hyperactivity disorder. Clin Pediatr. 1997;36:381-93.

19. Seeman P, Madras BK. Anti-hyperactivity medication: Methylphenidate and amphetamine. Mol Psychiatry. 1998;3: 386-96.

20. Cook EH, Stein MA, Krasowski MD, Cox NJ, Olkon DM, Kieffer JE, et al. Association of attention deficit disorder and the dopamine transporter gene. Am J Hum Gen. 1995;56:993-8.

21. Waldman ID, Rowe DC, Abramowitz A, Kozel ST, Mohr JH, Sherman SL, et al. Association and linkage of the dopamine transporter gene (DAT1) and attention-deficit/hyperactivity disorder in children. Am J Hum Genet. 1998;63:1767-76.
22. Ebstein RP, Novick O, Umansky R, Priel B, Osher Y, Blaine D, et al. Dopamine D4 receptor (DRD4) exon III polymorphism associated with the human personality trait of Novelty Seeking. Nat Genet. 1996;12:78-80.

23. Matsuomoto M, Hidaka K, Tada S, Tasaki Y, Yamaguchi T. Fulllength CDNA cloning and distribution of human dopamine D4 receptor. Mol Brain Res. 1995;29:157-62.

24. Barkley RA. Behavioral inhibition, sustained attention, and executive functions: constructing a unifying theory of ADHD. Psychol Bull. 1997;121:65-94.

25. LaHoste GJ, Swanson JM, Wigal SB, Glabe C, Wigal T, King N, et al. Dopamine D4 receptor gene polymorphism is associated with attention-deficit/hyperactivity disorder. Mol Psychiatry. 1996;1:121-4.

26. Faraone SV, Doyle AE, Mick E, Biederman J. Meta-analysis of the association between the dopamine D4 gene 7-repeat allele and attention-deficit/hyperactivity disorder. Am J Psychiatry. 2001;158:1052-7.

27. Lowe N, Kirley A, Hawi Z, Sham P, Wickham H,. Kratochvil CJ, et al. Joint analysis of DRD5 marker concludes association with ADHD confined to the predominantly inattentive and combined subtypes. Am J Human Genetics. In Press 2003.

28. Roman T, Schmitz M, Polanczyk GV, Eizirik M, Rohde LA, Hutz $\mathrm{MH}$. Further evidence for the association between attentiondeficit/hyperactivity disorder and the dopamine-betahydroxylase gene. Am J Med Genet. 2002;114:154-8.

29. Roman T, Schmitz M, Polankzick G, Eizirik M, Rohde LA, Hutz M. Association between $\alpha-2 a$ adrenergic receptor gene (adra2a) and Attention-Deficit/Hyperactivity Disorder. Am J Med Genet. 2003; 120B:116-20.

30. Quist JF, Barr CL, Schachar R, Roberts W, Malone M, Tannock R, et al. Evidence for the serotonin HTR2A receptor gene as a susceptibility factor in attention-deficit/hyperactivity disorder (ADHD). Mol Psychiatry. 2000;5:537-41.

31. Manor I, Eisenberg J, Tyano S, Sever Y, Cohen H, Ebstein RP, et al. Family-based association study of the serotonin transporter promoter region polymorhism (5-HTTLPR) in attention-deficit/ hyperactivity disorder. Am J Med Genet. 2001;105:91-5.

32. Seeger G, Schloss P, Schmidt MH. Functional polymorphism within the promoter of the serotonin transporter gene is associated with severe hyperkinetic disorders. Mol Psychiatry. 2001;6:235-8.

33. Tang G, Ren $D$, Xin R, Qian $Y$, Wang $D$, Jiang S. Lack of association between the tryptophan hydroxylase gene $A 218 \mathrm{C}$ polymorphism and attention-deficit/hyperactivity disorder in Chinese Han population. Am J Med Genet. 2001;105:485-8.

34. Auerbach JG, Benjamin J, Faroy M, Geller V, Ebstein R. DRD4 related to infant attention and information processing: a developmental link to ADHD? Psychiatr Genet. 2001;11:31-5.

35. Seeger G, Schloss P, Schmidt MH. Marker gene polymorphism in hyperkinetic disorder - predictors of clinical response to treatment with methylphenidate? Neurosci Lett. 2001;313:45-8.

36. Riesgo R, Rohde LA. A neurobiologia do TDAH. In: Kapczinski F, Quevedo JL, Izquierdo I, editores. Bases Neuroquímicas dos Transtornos Psiquiátricos 2nd ed. Porto Alegre: Artes Médicas; 2004. p 338-40.

37. Lefèvre $A B$. Exame Neurológico Evolutivo. In: Diament $A J$, Cypel S, editores. Neurologia Infantil-Lefèvre. 2nd ed. São Paulo: Atheneu; 1989. p.99-109.

38. Castellanos FX, Lee PP, Sharp W, Jeffries NO, Greenstein DK, Clasen LS, et al. Developmental trajectories of brain volume abnormalities in children and adolescents with attention-deficit/ hyperactivity disorder. JAMA. 2002;14:1740-8.

39. Pliszka SR, McCracken JT, Maas JW. Catecholamines in attentiondeficit/hyperactivity disorder: current perspectives. J Am Acad Child Adolesc Psychiatry. 1996;35(3):254-71.

40. Levy F, Farrow M. Working memory in ADHD: prefrontal/ parietal connections. Curr Drug Targets. 2002;2:347-52.

41. American Academy of Child and Adolescent Psychiatry (AACAP). Practice Parameters for the Assessment and Treatment of Children, Adolescents and Adults with Attention - Deficit/ Hyperactivity Disorder. J Am Acad Adolesc Psychiatry. 1997;36 Suppl 10:85-121.

42. Rohde LA, Biederman J, Zimmermann H, Schmitz M, Martins S, Tramontina S. Exploring age-of-onset criterion in Brazilian adolescents. European Child Adolesc Psychiatry. 2000;9:212-18.

43. Biederman J, Newcorn J, Sprich S. Comorbidity of attention deficit hyperactivity disorder with conduct, depressive, anxiety, and other disorders. Am J Psychiatry. 1991;148(5):564-77. 
44. Brown RT, Freeman WS, Perrin JM, Stein MT, Amler RW, Feldman HM, et al. Prevalence and assessment of attentiondeficit/hyperactivity disorder in primary care settings. Pediatrics. 2001;107:E43.

45. Biederman J, Milberger S, Faraone SV, Kiely K, Guite J, Mick E, et al. Impact of adversity on functioning and comorbidity in children with attention-deficit hyperactivity disorders. J Am Acad Child Adolesc Psychiatry. 1995;34:1495-503.

46. Kessenich M. Developmental outcomes of premature, low birth weight and medically fragile infants. NBIN. 2003;3:80-7.

47. Conners CK. Rating scales in attention-deficit hyperactivity disorder: use in assessment and treatment monitoring. J Clin Psychiatry. 1998;59:24-30.

48. Levine MD. The ANSER System. Cambridge: Educators Publishing Service; 1980.

49. Halasz G, Vance AL. Attention-deficit/hyperactivity disorder in children: moving forward with divergent perspectives. Med JAust. 2002;177:554-7.

50. Guardiola A. Distúrbio de hiperatividade com déficit de atenção: um estudo de prevalência e fatores associados em escolares de $1^{\text {a }}$ série de Porto Alegre [tese]. Porto Alegre(RS): UFRGS; 1994.

51. Wechsler D. WISC-III/Manual. New York: The Psychological Corporation; 1991.

52. American Academy of Pediatrics - Subcommittee on AttentionDeficit/Hyperactivity Disorder. Clinical practice guideline: treatment of the school-aged children with attention-deficit/ hyperactivity disorder. Pediatrics. 2001;108:1033-44.

53. Barkley RA, Fischer M, Edelbrock CS, Smallish L. The adolescent outcome of hyperactive children diagnosed by research criteria: I. an 8-year prospective follow-up study". J Am Acad Child and Adolesc Psychiatry. 1990:29:546-57.

54. Biederman J, Wilens $T$, Spencer T. Diagnosis and treatment of adult ADHD. In: Pollack MH, Otto MW, Rosenbaum JF, editors. Challenges in clinical practice: pharmacologic and psychosocial strategies. New York: Guilford Press; 1996. p. 380-406.

55. American Academy of Pediatrics. Clinical Practice Guideline: treatment of school age children with ADHD. Pediatrics. 2001; 108:1033-44.

56. Rohde LA, Benczik E. Transtorno de déficit de atenção/ hiperatividade: O que é? Como ajudar? Porto Alegre: Artes Médicas; 1999.

57. Knapp P, Johannpeter J, Lyszkowski LC, Rohde LA. Terapia Cognitivo-Comportamental no TDAH: Manual do terapeuta. Porto Alegre: Artes Médicas; 2003.

58. The MTA Cooperative Group. A 14- month randomized clinical trial of treatment strategies for attention- deficit/ hyperactivity disorder. Arch Gen Psychiatry. 1999;56:1073-86.
59. Greenhill LL, Halperin JM, Abikoff H. Stimulant medications. J Am Acad Child Adolesc Psychiatry. 1999;38:503-12.

60. Spencer $T$, Biederman J, Wilens $T$, Harding M, O'Donnell $D$, Griffin S. Pharmacotherapy of attention-deficit hyperactivity disorder across the life cycle. J Am Acad Child Adolesc Psychiatry. 1996;35:409-28

61. Wilens TE, Spencer T. Combining metthylphenidate and clonidina. J Am Acad Child Adolesc Psychiatry. 1999;38:614-6.

62. Spencer TJ, Biederman J, Harding M, O'Donnell D, Faraone SV, Wilens TE. Growth deficits in ADHD children revisited: evidence for disorder-associated growth delays? J Am Acad Child Adolesc Psychiatry. 1996;35:1460-9.

63. Wilens T, Faraone S, Biederman J, Gunawardene S. Does stimulant therapy of ADHD beget later substance abuse: a metanalitic review of the literature. Pediatrics. 2003;11:179-85.

64. Martins S, Tramontina S, Polanczyk, G, Eizirik M, Swanson J, Rohde LA. Weekend holidays with methylphenidate use in ADHD children: a randomized clinical trial. J Child Adolesc Psychopharmacol. In Press 2003.

65. Gutgesell H, Atkins D, Barst R, Buck M, Franklin W, Humes R, et al. Cardiovascular monitoring of children and adolescents receiving psychotropic drugs. Circulation. 1999;99:979-82.

66. Emslie GJ, Walkup JT, Pliszka SR, Ernst M. Nontricyclic antidepressants: current trends in children and adolescents. J Am Acad Child Adolesc Psychiatry. 1999;38:517-27.

67. Connor DF, Fletcher KE, Swanson JM. A meta-analysis of clonidine for symptoms of attention- deficit hyperactivity disorder. J Am Acad Child Adolesc Psychiatry. 1999;38:1551-9.

68. Biederman J, Kratochvil CJ, Spencer T, Wozniack J. Determining and achieving therapeutic targets in ADHD. J Clin Psychiatry. $2003 ; 64: 265-76$.

Corresponding author:

Luis Augusto Rohde

Serviço de Psiquiatria da Infância e Adolescência

Hospital de Clínicas de Porto Alegre $-4^{\circ}$ andar

Rua Ramiro Barcelos, 2350

CEP 90035-003 - Porto Alegre, RS, Brazil

Tel./fax: +55 (51) 3321.3945

E-mail: Irohde@terra.com.br 